\title{
LAS OCTAVAS REALES EN LOS AUTOS SACRAMENTALES DE PEDRO CALDERÓN DE LA BARCA Y SU IMPLICACIÓN DRAMÁTICA
}

\author{
Carlos Mackenzie \\ Universidad Autónoma Metropolitana-Iztapalapa
}

\begin{abstract}
RESUMEN: Las octavas reales son un sistema estrófico poco común en el teatro de Pedro Calderón de la Barca, por lo menos en sus obras seculares; sin embargo, es más frecuente encontrar este estilo métrico italiano en sus autos sacramentales, así que vale preguntar cuál es el uso que le da Calderón; para responder, además de analizar los pasajes escritos en octavas, es posible hacer contraste entre éstas y las silvas pareadas, para saber no sólo la función que cumplen, sino matizar con otro estilo métrico italiano que es frecuente en el teatro calderoniano.
\end{abstract}

PALABRAS CLAVE: Octavas reales, versificación, silvas, auto sacramental.

\section{LES OCTAVAS REALES DANS LES AUTOS SACRAMENTALES DE PEDRO CALDERÓN DE LA BARCA ET S'IMPLICATION DRAMATIQUE}

\begin{abstract}
RÉSUMÉ: Les octavas reales sont un système de versification peu commun dans le théâtre de Pedro Calderón de la Barca, au moins dans ses oeuvres séculières; cependant, il est plus fréquent de trouver ce style métrique italien dans son autos sacramentales, telle qu'il vaut de demander quel est l'usage qui lui donne Calderón; pour répondre, en plus d'analyser les passages écrits dans des octavas, il est possible de faire un contraste entre celles-ci et les silvas pareadas, pour savoir non seul la fonction qu'ils accomplissent, mais nuancer avec un autre style métrique italien qui est fréquent chez le théâtre caldéronien.
\end{abstract}

MOT CLES: Octavas reales, versification, silvas, auto sacramental.

Las octavas reales sufrieron un cambio de paradigma al pasar de la poesía lírica a la poesía dramática de la Comedia Nueva. En gran medida, las octavas lle- 
varon a cuestas (aunque no de forma exclusiva) la función de la lírica épica y mitológica"; para la Comedia Nueva, Lope de Vega escribe "las relaciones piden romances,/ aunque en octavas lucen por extremo" (vv. 309-310); resulta obvio que hay que tomar estas palabras con pinzas, pues no se trata de un dogma -o el mismo Lope hubiera faltado a él-, sin embargo sirve para contemplar el cambio paradigmático de su uso. Debe de existir, sobre todo, porque se trata de dos tipos de literatura distintos ${ }^{2}$, con necesidades, caminos y finalidades distintas, como apunta Begoña López Bueno, "Los géneros son, desde luego designaciones de grupos, y [...] los principios de formación de grupos son de especie absolutamente diversa, pues bien son externo-formales, o bien se refieren al contenido" (1992: 99); aunque sean versos, y aunque se trate del mismo tipo estrófico, la diferencia, incluso podríamos decir evolución, radica en el género literario al que pertenecen.

Si dicho cambio (pasar de la lírica épica a la sugerencia -algunas veces cumplida-de las relaciones) puede resultar un tanto drástico, así como pasar del uso que pide Lope a la práctica, y más tratándose de un dramaturgo posterior a él, la brecha paradigmática podría ser aún más profunda. Rozas (2003) ve en los versos dedicados a la polimetría en el Arte nuevo de hacer comedias, un ejemplo de cómo se deben acomodar los versos "con prudencia" (Lope vv. 305), es decir, los seis versos sirven para expresar que se debe acomodar los estilos métricos según la manera en que el dramaturgo planea desarrollar el drama, los temas, el tipo de lenguaje, los personajes; en otras palabras, la función de los estilos métricos está sujeta al contenido, una de las dos partes que menciona López Bueno, como acabamos de ver. Desde esta perspectiva, y justo como había insistido, la versificación no tiene por qué obedecer punto por punto lo que Lope ejemplifica ${ }^{3}$, menos tratándose de un autor posterior. Calderón no sólo es un dramaturgo que forme parte de la llamada segunda generación de dramaturgos, se trata del autor de comedias que se toma como parteaguas, pues "abre una segunda fase de la comedia, en la que elementos heredados y nuevas invenciones alcanzarán con Calderón su fusión culminante" (Arellano 2001: 23); además de llevar al auto sacramental a su "estado más perfecto y complejo, más rico de medios y de estructuras más elaborada” (Arellano y Duarte 2003: 123), también se caracteriza

1. También sería injusto afirmar que la poesía épica y mitológica sólo se escribían en octavas; hay algunos testimonios de este tipo de composiciones en tercetos y endecasílabos; ver Palomares y Palomares 14.

2. No olvido que se trata un espectáculo audio-visual; no obstante, el proceso de escritura es anterior a la puesta en escena; durante éste, se hace selección de versos y todo lo concerniente a la estructura literaria.

3. También hay que recordar que la polimetría ya estaba en uso desde antes del Arte nuevo; además de no ser una innovación del Fénix, él mismo la practicaba sin establecer preceptos explícitos, más bien se intuían -echando mano de la imitatio tan frecuente en el Siglo de Oro. 
por simplificar, más que la función, el número de estilos métricos y las variaciones de éstos; según Rozas, Calderón reduce tanto cambios como sistemas estróficos y aestróficos (2003: 60), esto con relación al teatro de Lope, que usó casi todos los tipos de versos que existían en el momento, si no es que utilizó todos; también al simplificar, otros estilos fueron desechados (aunque no de manera permanente) y otros que disminuyó considerablemente su uso.

Entre los cambios más notorios, encontramos el aumento del uso de romance a expensas de las redondillas, cuya disminución implica una especialización mayor en cuanto a su función; al aumentar el porcentaje del romance, también afectó el número de cambios métricos incluidos en cada obra, pues las extensas tiradas en romance en ocasiones alcanzan hasta seiscientos versos de una sola jornada; asimismo, los versos endecasílabos son disminuidos en gran medida, mucho más que los versos de origen español, dejando, según el género dramático, espacio para las silvas, y en el caso de los autos sacramentales, para las octavas. Hago esta distinción, porque es más usual el uso de silvas en el teatro para corral (obras de capa y espada y de corte trágico), siendo más escaso el uso de octavas reales; en el género sacramental, este estilo de versificación es algo más común encontrarlo, quizá no de manera abundante (hablando del porcentaje utilizado en las obras), pero sí con más frecuencia.

Ya desde el congreso dedicado a Calderón por motivo del tercer centenario de su muerte, celebrado en 1981, Gerd Hofmann hacía este planteamiento:

Sabemos que el verso básico del teatro español del Siglo de Oro es el octosílabo, de origen castellano, en sus diversas combinaciones, estróficas o no, rimadas, o asonantadas. Sería interesante preguntarse hasta qué punto los versos de origen italiano podían tener, a más de cien años de su introducción en España, en el contexto de los autos calderonianos y entrando en oposición estructural con los metros de origen y tipo diferente, el carácter de una cosa extraña, pero de engañadora belleza (1983: 1130).

Después de poco más de veinte años, aún no hay (o por lo menos hasta donde mi documentación bibliográfica me ha permitido tener noticia) un estudio sobre las formas italianas que Pedro Calderón usa en sus autos sacramentales, menos uno enfocado a las octavas reales, aunque ya se han hecho acercamientos brillantes a la silva en su teatro de corte trágico (Fernández 2008a; 2008b) y en sus comedias de capa y espada (Fernández 2010) ${ }^{4}$; con estos ejemplos lo que se infiere es un in-

4. También existe interés, por ejemplo, en los sonetos en el teatro de Lope de Vega (Romanos). 
terés también por la interpretación de las formas métricas cuyo uso no fue extenso -comparándolo con el romance o las redondillas, de uso más amplio-; la utilización de las octavas tuvo un sentido específico, dado que no se prescindió de ellos en su totalidad, por lo menos un segmento de varias obras sacramentales está escrito en este sistema estrófico. Un estudio que comprenda todas las formas métricas italianas en todo el corpus de autos calderonianos supondría un trabajo bastante exhaustivo y demasiado largo -digno de una monografía completa-, así que, por el momento, limitaré el estudio a cinco obras: El pleito matrimonial del cuerpo y el alma, El divino Orfeo (la primera versión, de 1634), La cena del rey Baltasar, La hidalga del valle y La torre de Babilonia; en ellas, me ocuparé únicamente de las octavas reales.

La elección no es gratuita, ni de las obras ni de los estilos, los cinco autos seleccionados son muestra de la manera en que Calderón utiliza dicho tipo de versificación dentro de un marco cronológico de diez años aproximadamente (la fecha de las obras se han ubicado entre los años 1630 a 1639); la elección de las octavas reales obedece a que se tratan de un estilo métrico italiano que resulta usual hallarlo en las obras sacras de Calderón, junto a las silvas - de la que haré mención para hacer contraste-, y en ambos casos, se entrecruzan funciones y usos de uno y otro, aunque no se sustituyen, pues en varias obras aparecen juntas. En términos porcentuales, es obvia (y sabido de sobra) la apabullante cantidad que alcanza el romance; es indiscutible la preeminencia, en general, del verso español -octosílabo- frente a los endecasílabos; aún hay que observar, entre el bajísimo uso de los estilos de origen italiano, cuales son los que dicho dramaturgo prefirió; gracias a Leonor Fernández, sabemos que la silva tuvo un buen lugar cuando Calderón de la Barca seleccionaba los estilos métricos en sus dramas y sus comedias de capa y espada; algo diferente sucede con los autos sacramentales, pues no sólo las silvas, también las octavas son frecuentes (a diferencia de los tercetos, sonetos, liras en sus distintas combinaciones, endecasílabos sueltos, estancias, etcétera, cuya aparición es casi esporádica).

Como mencionó Hofmann, los sistemas métricos traídos de Italia durante el Renacimiento, están de alguna manera ligados a las "fuerzas del mal", al Demonio y los diversos personajes que lo encarnan en los autos sacramentales. Sin embargo, hay que hacer precisiones y matices, pues no todos los estilos de versificación extranjera funcionan de la misma manera, ni contienen en sí asuntos problemáticos o temas y situaciones que tengan que ver con la perdición de los personajes, por lo menos no de manera directa, así como no todos los diálogos de las fuerzas malignas se escriben en estos tipos de versificación. Según Marín, que tomó como base cinco autos sacramentales, dice acerca de las octavas reales: 
La octava real tiene en Calderón mucha menor frecuencia que en Lope [...] Pero, como siempre, Calderón parece continuar la última tendencia del Fénix, quien fue aumentando su uso para monólogos [...] En efecto, Calderón las utiliza para monólogos de tipo diverso en 10 comedias y para diálogo sólo en 4 , siempre del mismo carácter informativo sobre asuntos graves y en tono factual, pero con fuerte tensión dramática. En cambio, los monólogos pueden ser alocuciones encomiásticas o elegíacas en estilo culto y solemne, o comentarios del personaje sobre su propia situación, o «relaciones» de tema público [...] Así vemos que Calderón al reducir la proporción de octavas en su sistema versificador, tiende a especializar su uso más que Lope, dedicándolas siempre a asuntos graves, en estilo elevado y más o menos culto (2000: 357).

Según lo que he observado en mi lectura de los autos que seleccioné de Calderón de la Barca, así como hay puntos de convergencia, existe heterogeneidad en cuanto a su uso; en La cena del rey Baltasar, La hidalga del valle y en cierta medida en El divino Orfeo, las octavas se usan para monólogos, aunque no precisamente del mismo tipo; en las otras dos, El pleito matrimonial del cuerpo y el alma y La torre de Babilonia, se ocupan como diálogos encomiásticos e informativos, es decir, meramente factual. Los monólogos no son precisamente "relaciones", en el sentido de que narran algún suceso, haya sucedido en escena o no, sino que se trata de una explicación que ayuda a caracterizar a algún personaje (aunque no es un recurso exclusivo de este tipo de parlamentos, como señalaré posteriormente) o la descripción, en tono elevado, de algún lugar.

En La cena del rey Baltasar, Daniel acaba de encontrarse con el rey, lo enfrenta en el nombre de Dios, sin embargo, no logra más que molestar al regente; al marcharse y quedar solo, y preguntar quién será el que tome venganza del agravio que el rey, junto a Idolatría y Vanidad, hacen a la cristiandad, la Muerte se presenta con Daniel como su aliado en contra de Baltasar; dicha introducción de este personaje, escrito en octavas, nos ofrece una descripción en tono elevado y lleno de referencias bíblicas. Se trata de una relación sobre el origen de la Muerte:

Yo, divino profeta Danïel,
de todo lo nacido soy el fin;
del pecado y de la envidia hijo cruel,
abortado por áspid de un jardín.
La puerta para el mundo me dio Abel,
mas quien me abrió la puerta fue Caín.

(1970: vv. 652-657)

Así mismo, le cuenta a Daniel la razón de su aparición: es enviado por Dios para ayudarlo a vencer a Baltasar y sus concubinas, pues siendo Daniel el juicio, 
la palabra, y la Muerte es la ejecución, la acción del juicio de Dios, entre ambos podrán restaurar el orden y la voluntad divina. La relación que ofrece sobre sí misma ayuda a advertir algunos aspectos que caracterizan a la Muerte: su sed por despojar de la vida a quienes desea, expresa el poder de su jurisdicción, de la que nadie escapa, lo que también deja ver cierta prepotencia del personaje.

La hidalga del valle es un auto escrito para la defensa y afirmación de la inmaculada concepción de María; en este caso, las octavas reales están en voz de Furor, Naturaleza humana y Culpa. Esta última, va pasando por las tres leyes (ley natural, ley escrita y ley de gracia), representadas cada una por una puerta (y un carro de los cuatro que sirven para la apuesta en escena), para cobrar el tributo que se le debe por ser concebidos en pecado; trae consigo como esclava a la Naturaleza humana. Al llegar a la última puerta, la Gracia se niega a pagar el tributo, enojada la Culpa, y estando en escena con Furor y Naturaleza, comienza la primera parte de las octavas reales, que consisten en el monólogo de Furor, que narra, a petición de la Culpa, desde los abuelos de María, hasta llegar al próximo nacimiento de esta; al ser anunciado su nacimiento, la naturaleza misma, según la relación del personaje, da señales de alegría (el canto de las aves, la armonía del sonido del movimiento de los árboles, el murmullo del río junto a su claridad pura, que pasa a ser un símbolo de María). Interviene con un breve parlamento la Naturaleza al terminar el monólogo, que consiste en una octava, y en ella, expresa esperanza de ser liberada de su esclavitud y dejar de estar a merced de Culpa y Furor; al terminar, aparece una quintilla cantada por "Amor y responde toda la música" (1957: v. +636), en términos de Marc Vitse (49-50 $)^{5}$, se trata de un texto englobado que refuerza la esperanza de la Naturaleza y el temor de Furor y Culpa; continúan la versificación italiana, en esta ocasión es Culpa quien habla, airada por el contenido de la canción:

Culpa: ¿Qué importa que amor cante si yo, fuerte

y soberbia de ti humilde y cautiva

los triunfos borraré y aun de otra suerte

he de vencer tu vanidad altiva?

Si en esta anunciación la gloria advierte,

presto en su concepción haré que escriba

esa Niña en mi libro el vasallaje

que debe pro nacer de tu linaje.

(1957: vv. 642-649)

5. Vitse en este trabajo ofrece nuevos criterios para poder considerar un tipo de versificación intercalado en otro como englobado por su adialogicidad, interlocutividad y su intermetricidad. 
La misma enumeración que usó Furor para expresar la armonía del nacimiento de María, la retoma Culpa con la finalidad de expresar que tal será perturbada por su malicia, haciendo pagar el pecho que debe cada ser humano, "pues, ¿para concebirse con pecado, anunciada qué importa que haya sido?" (1957: vv. 652-653). En esta parte de las octavas, a diferencia de Furor, Culpa se muestra como un personaje altivo y arrogante -alegoría del demonio, al fin-, que no está dispuesto a fracasar en su empresa y hacer pagar a la recién nacida lo que se le debe, pues ignora que ella nacerá sin pecado concebida.

El monólogo en octavas que aparece en El divino Orfeo en boca de Aristeo -alegoría del demonio-, es una descripción alambicada y muy al estilo gongorino del lugar donde se desarrolla la acción. Aristeo convence mediante engaños a Eurídice de seguirlo, afirmando ser un príncipe desterrado, y ofreciéndole una vida llena de banalidades, a diferencia de la que llevaba como pastora con su esposo Orfeo. Antes de la intervención de Eurídice, Aristeo hace notoria la alegoría:

Hoy que la alegoría en mí se acaba
Plutón me nombro, en cuyo nombre leo
ser el absoluto dueño del Leteo.
Hablen testigos ciertos
que construyen Plutón Dios de los muertos.

(1999: vv. 1266-1270)

Los dos últimos versos citados tienen forma de silva pareada (un heptasílabo y un endecasílabo) que queda inmersa en las octavas; según los criterios ya mencionados que propone Vitse, carecen de adialogicidad, pues son parte de un monólogo que inmediatamente contesta Eurídice, así como de interlocutividad, pues no se trata de un par de versos aislados que hablen de alguna materia distinta a la que ya se hablaba. La intervención de Eurídice, que sólo abarca una octava, tiene una función inversa a la intervención de Naturaleza en La hidalga del valle; después de ello, hay un terremoto -señal de que Orfeo ha entrado al inframundo en busca de su esposa-, y de nuevo, como monólogo, Aristeo narra lo que acontece -el, terremoto, un eclipse, oscuridad total del cielo-, y puede considerarse cierto miedo e identificación, dentro de la exclamación y sorpresa del personaje, de lo que sucede según su parlamento y su sentir. Considero inversas las intervenciones porque en La hidalga del valle, Furor muestra cierto miedo de que nazca inmaculada María y no se les pague tributo en la tercera ley, después de que Naturaleza dice su parlamento, Culpa se muestra arrogante y decidida a que no quede exenta de pago la era de la Ley de Gracia; en El divino Orfeo, primero Aristeo se muestra arrogante y poderoso, después del parlamento de Eurídice -en el que acepta que 
ha desobedecido a su esposo-, comienza a temer al ver tantos sucesos que, según el texto, son señal de que Orfeo ha pasado el Leteo.

En las dos últimas obras que abordaré, las octavas se desarrollan en diálogos. En El pleito matrimonial del cuerpo y el alma, comienza con este tipo estrófico, se trata de un diálogo encomiástico entre el Pecado y la Muerte. Algunos versos que evocan a la Muerte son muy semejantes a los que utiliza este mismo personaje en La cena del rey Baltasar: "Introducido escándalo de Abel” (1967: v. 13). Las octavas, en gran medida, son epítetos con que cada uno se evoca; Pecado es quien llama a la Muerte, que se encuentra dentro de un árbol -del bien y del mal-; el primero pide ayuda al segundo para lograr quedarse con el Alma, pues la desea desde que la vio, y Muerte no se niega a brindarle ayuda; a diferencia del personaje homónimo de La cena del rey Baltasar, en donde la Muerte está del lado de Dios, aquí se presenta como alguien neutral, que ayuda a quien se lo pida, sin reparar en la intención; por ello, acepta ayudar a Pecado. Las seis octavas que sirven de inicio, permiten reconocer inmediatamente a los primeros personajes que salen, en un estilo elevado y acumulando epítetos que dan características de los personajes, hasta que al final se revela exactamente quienes son.

En las octavas de La torre de Babilonia intervienen más personajes en el diálogo, aunque en principio, más que diálogos, son breves monólogos de los nietos de Noé, pues no interactúan entre ellos, más bien, a manera de prosopopeya, 'hablan' con la peña para preguntar si en ese lugar vive su abuelo: "Heber: Alto monte de Armenia, cuya cumbre/ al cielo sube sin fatiga alguna" (2008: vv. 759-760), luego "Arcener: Alto monte de Armenia, que ceñido/ de nieve y matizado de colores" (2008: vv. 766-767); asimismo, los criados de cada uno, hacen un eco burlesco de los parlamentos de sus amos, la diferencia en este caso, es que el parlamento de Heber y Arcener son de una octava, mientras que para los dos criados son cuatro versos para cada uno. Noé aparece en escena, los reconoce y les da la bienvenida; de manera muy breve, cada uno dice de dónde viene y de quién es descendiente; después del recibimiento de Noé a sus nietos y un breve diálogo -donde igual participan los graciosos como contrapunto de los parlamentos de reconocimiento y afecto-, aparece el bisnieto de Noé, Nembrot, cuya altanería y soberbia, junto al vestuario e imagen construidas por las didascalias implícitas y explícitas, dan a entender que su visita no es solamente porque vaya a buscar al iniciador de su estirpe, ni por obedecer preceptos, "sino por sólo gusto mío, a efeto/ del ver el mundo la circunferencia, / por ver si puedo avasallarla toda" (2008: vv. 851-853). Ante esto, su bisabuelo le advierte que nadie puede contra la ira de Dios, y que si pudo destruirlo todo con el Diluvio, lo podrá hacer de nuevo; la respuesta, 
como se espera, es de soberbia, arguyendo que sólo supieron de ese acontecimiento de oídas y desconoce la dimensión que verdaderamente tuvo.

Este segmento de la obra presenta de manera somera (pues anteriormente supimos cómo se iban los hijos de Noé a poblar el mundo, y que ellos mandarían a sus descendientes a informarle cómo les ha ido con el pasar de los años), pues no se necesita más que una exordio de presentación de cada uno de los recién llegados, y como vimos, a manera de prosopopeya. Asimismo, la llegada de Nembrot significa la introducción (ya adelantada con la soberbia de Cam) del elemento perturbador de la obra, pues este personaje es el antagonista, quien reta a Dios a destruir su estirpe, pues supone que si construye la torre y balsas resistentes (de piedra) no podrá detenerlo.

En las cinco obras, además de esta distinción entre monólogos y diálogos (que en realidad, los diálogos son escasos, salvo El pleito matrimonial del cuerpo y el alma), hay situaciones semejantes que se desarrollan en octavas: representan una pausa en el desarrollo de la trama, el ritmo dramático disminuye y da paso a narraciones 'monologadas' o parlamentos breves. Como vimos en La torre de Babilonia, se tratan de breves monólogos ${ }^{6}$ que apenas se extienden a una octava por parlamento; la condición de relación tiene ciertas restricciones que deben ser tomadas en cuenta: no se trata de sucesos que hayan acontecido o no en la diégesis de la obra, sino de caracterizaciones, de encumbramientos de personajes que existan o no en el tablado (como la mención de Dios, que resulta obvio que no aparece en escena), de descripciones alambicadas, de sintaxis compleja y lenguaje culto (que en ocasiones, se identifica con el personaje, su caracterización o su forma de actuar dentro del auto).

Los personajes de la Muerte que aparecen en La cena del rey Baltasar y El pleito matrimonial del cuerpo y el alma hacen su primera intervención con octavas, en el primer caso, para presentarse, en el segundo para ser presentado y presentar a otro personaje. En ambos casos, su aparición tiene que ver con las fuerzas del mal: en la primera obra, como ya mencioné, aparece para detener a Baltasar, mientras en la segunda, aparece para socorrer al Pecado, en apariencia está del lado del antagonista (aunque esta unión resulta temporal). En La hidalga del valle, las octavas están en boca (mayoritariamente) de Furor y Culpa, y la intervención de la Naturaleza humana sirve como puente entre la narración que ayuda a entender la

6. Quizá hasta podría considerarse como soliloquio, si se toma en cuenta que no hay un receptor para cada parlamento, por lo menos los de Arcener y Heber, que se dirigen a un objeto inanimado. 
era de gracia y por qué no pagarán el debido pecho y la ira de Culpa que expresa al enterarse de esa noticia; así que en cierta medida, no sólo se vincula a las fuerzas malignas las octavas por estar en boca del antagonista, sino que planea que a toda costa se cumpla el precepto del pecado original, sin importar la anunciación.

La descripción en octavas reales que aparece en El divino Orfeo, cuya sintaxis es compleja y alambicada, nos ofrece un espacio más allá de la escena, pero no se limita a romper las barreras de la escenografía, adjetivar constantemente guía la imaginería al lugar lóbrego y triste en el que efectivamente están, también crean una sensación del ambiente en el que se desenvuelve el cuadro; después del parlamento de Eurídice -justo cuando termina, Orfeo ha cruzado el Leteo-, Aristeo deja este tipo de narración, y la que continúa, más que ambientar, nos advierte que la descripción puede corresponder con el sentir del personaje, pues sabe que la reacción del cielo y la tierra -el eclipse y el terremoto-, son avisos de que Orfeo ha llegado al inframundo, y perturbado, cierra el monólogo con un despliegue de soberbia.

Existe cierto vínculo con las fuerzas del mal en los ejemplos mencionados, pero no se concreta del todo alguna situación que haga que la trama sea más complicada o grave, salvo El divino Orfeo, que en octavas ya Eurídice fue llevada al inframundo; salvo esto, se tratan de expresiones de soberbia -como las de Aristeo, Culpa, Muerte ( la que aparece en El pleito matrimonial del cuerpo y el alma), Nembrot-, es decir, la ya mencionada autocaracterización en los distintos monólogos, las descripciones, ya sea breve o sea extensa, pone en evidencia que dicho personaje (salvo la Muerte de La cena del rey Baltasar, que aparece por mandato divino para socorrer a Daniel) está dispuesto a perturbar la paz, a vencer a los protagonistas o simplemente, retar la creencia cristiana, pero siempre en ellas hay expresiones de soberbia y altivez. Coincide en cierta medida con una de las funciones de la silva que Leonor Fernández notó en los dramas calderonianos: "Se trata de monólogos o soliloquios reflexivos en los que externa su temor, confusión, extravío, perturbación, tristeza, rencor, odio, celos, remordimiento, desesperación" (2008b: 110; las cursivas son mías); sin embargo, las octavas no suplen las silvas.

En dos obras del corpus que elegí no existen pasajes en silvas, se tratan de El pleito matrimonial del cuerpo y el alma y La hidalga del valle; es posible pensar que las octavas puedan funcionar como sustituto de las silvas, pues ambos estilos italianos, según mencioné hace un momento, tienen puntos de comunión; no resulta ocioso observar de qué forma funcionan en las tres obras que sí conviven las octavas y las silvas, pues podría ayudar a precisar y/o matizar aún más 
el uso de ambas en el género sacramental ${ }^{7}$. En contraste, las silvas que se presentan en La cena del rey Baltasar sirven de monólogos encomiásticos durante la boda del rey de Babilonia con Vanidad e Idolatría, que presencia escondido Daniel junto a Pensamiento, un uso distinto al que se da a las octavas en esta misma obra; como mencioné, la Muerte en octavas reales hace su aparición para ayudar a Daniel y restablecer la palabra de Dios; incluso, en esta obra, las silvas sí están vinculadas directamente con las fuerzas del mal, pues en ellas se desarrolla la boda de Baltasar. El divino Orfeo abre con quince silvas (treinta versos en total), en boca de Aristeo, que describe, desorientado, el lugar al que acaba de llegar -y recién expulsado del paraíso, según el v. 7 "¿qué tierra es esta que piso?"-, se trata del caos del mundo antes de ser formado el Edén que habitarán Orfeo y Eurídice; en esta ocasión, ambos estilos italianos están en boca del mismo personaje, y ambos se ocupan de dar una descripción del lugar donde se encuentra, pero expresan cosas distintas: el primero confusión, el segundo exaltación y temor. La torre de Babilonia también empieza con silvas pareadas; los personajes, Noé, sus hijos y sus respectivas esposas, acaban de pasar por un trance difícil: el diluvio. Asimismo, se desarrolla el roce que existe entre Noé y su hijo Cam, amenaza éste acerca de que su estirpe será la mejor y dominará todo el mundo (como queda comprobada la misma ambición en su nieto Nembrot durante las octavas reales). Existen dos momentos en que la soberbia se expresa, sin embargo, el momento es más largo en el pasaje en silvas; otra diferencia, es que en octavas no hay ningún momento de tensión o algún suceso grave, lo que sí sucedió en silvas (el diluvio).

En las obras que sólo incluyen octavas reales es de notar que su función es más próxima al de las silvas. Mencioné que hay punto de encuentro (de similitud, vaya) entre ambos estilos, pero en las obras que carecen del sistema aestrófico, existe una cercanía aún más estrecha en cuanto a los usos, aunque no llegan a coincidir en su totalidad (por lo menos en los autos citados). En El pleito matrimonial del cuerpo y el alma se planea la perdición del Alma, es decir que caiga en tentación para que Pecado pueda poseerla, por lo que llama y pide ayuda a la Muerte, pues sólo este personaje tiene jurisdicción sobre el Cuerpo, futuro esposo del Alma. En La hidalga del valle Culpa es quién amenaza y se dispone a imponer su voluntad y expresa, además de soberbia, una enorme ira por aquellos que se atreven a desafiar sus preceptos (los que habitan en la era de Gracia). En estas obras, las octavas

7. Aunque cabe subrayar que aún falta un estudio más profundo que aborde solamente las silvas, como los ya mencionados trabajos de Leonor Fernández en las obras trágicas y cómicas de Calderón. 
están directamente vinculadas con las fuerzas del mal, y como ha sucedido con la silva, sirven para introducir el elemento perturbador, y es explicado por el mismo que quiere llevar a cabo el suceso maligno de cada obra. También es de mencionarse que los pasajes en silvas son más extensos que los que están en octavas, sobre todo cuando aparecen en la misma obra, pues las octavas de La hidalga del valle tienen una extensión considerable con relación a los demás pasajes del dicho sistema estrófico que aparece en las demás obras, y este auto sacramental, como ya mencioné, no tiene silvas.

En gran medida, Hofmann intuyó la relación entre los estilos métricos italianos y las fuerzas malignas que intervienen en los autos sacramentales de Pedro Calderón de la Barca; o para ponerlo en términos menos subjetivos (a diferencia de "la engañadora belleza", "la extrañeza" que menciona el estudioso alemán), las acciones, las amenazas, la expresión de altivez y la soberbia, el planteamiento de la caída de los personajes, la tentación, trampas, mentiras y embustes para hacerles pecar, para que no alcancen la gloria divina, son tema frecuente en las octavas. Parece ser que Calderón tuvo presente el uso de las octavas reales para dar una relación que explica cierta situación dramática, uso bastante curioso considerando que para la década de 1630 ya era muy común utilizar el romance para cualquier tipo de relaciones, aunque como todo, hay excepciones ${ }^{8}$. No se trata, en el caso de La hidalga del valle, sólo de informar, de explicar las palabras con que Gracia se niega a pagar el pecho a Culpa, desata la ira de éste, además de que se continúa, sin cambiar, con las octavas, por los que la causa/reacción se engloban en un mismo estilo métrico.

Así, después de tener el favor de los poetas para escribir lírica épica, de ser elegido por Lope de Vega para relaciones, vemos el uso que Calderón le da, pues, como mencioné al principio de este trabajo, el cambio paradigmático se da al pasar de un género literario a otro, aunque el estilo alambicado y culto (semejante al de Góngora, en específico su poema Polifemo y Galatea) se conservó, baste de ejemplo el relato de Aristeo en El divino Orfeo. Las octavas en el teatro sacramental de Calderón tienen una relación no tan estrecha -como pudiese suceder con las silvas- con las fuerzas del mal, pero es de resaltar que cada pasaje del estilo métrico italiano es parte de los parlamentos de los personajes malignos, en los que amenazan a los protagonistas, sea de manera directa o no; en el caso

8. Por ejemplo, el drama de La hija del aire, la relación con que se presenta Lidoro es con octavas reales; elección nada gratuita por parte de Calderón, pues este personaje resulta esencial, aunque no lo aparente, en ambas partes de esta tragedia. 
de las narraciones descriptivas se utiliza para ambientar y ayudar a crear una escenografía más lóbrega, como en El divino Orfeo; el caso de los diálogos encomiásticos, el de Muerte y Pecado, se dirigen al otro mediante sus características y orígenes.

Los estilos italianos, tanto silvas como octavas reales, no obtiene su importancia de la cantidad de versos o de ocasiones en que aparecen en el drama; como ya había notado Diego Marín, los versos de origen extranjero son realmente escasos, pero se equivoca al decir que carecen de importancia, o que ésta es mínima; ya se ha dicho mucho acerca de que si un estilo métrico abunda demasiado, se tiende a un uso general, y por el contrario, cuando se reduce, se especializa su uso, y como he intentado mostrar, las octavas no resultan tan insignificantes dentro del género sacramental, pues comparte con las silvas la introducción de los personajes malignos, de las situaciones graves, del los augurios de malos sucesos, sin coincidir del todo, como había mencionado, ni suplir un estilo con otro. Su importancia radica ahí, en el uso y la manera que Calderón captura la atención auditiva; quizá un estudio más amplio ayude a precisarlo, o si existió algún cambio de paradigma dentro de los autos sacramentales, pues el corpus que manejé, tiene como marco temporal la década de 1630 a 1639, por lo que es posible, en autos escritos después de dicha fecha, que su uso cambie. Por el momento, me limito a afirmar la gran importancia de las octavas, su vínculo con los elementos perturbadores y los personajes malignos que intuía Hofmann, pero que nadie había hecho ese acercamiento.

\section{Bibliografía}

ARELLANO, I. (2001). Calderón y su escuela dramática. Arcadia de las Letras 6. Madrid: Laberinto.

ARELLANO, I. y DUARTE, J. E. (2003). El auto sacramental . Arcadia de las Letras 24. Madrid: Laberinto.

CALDERÓN DE LA BARCA, P. (2008). La torre de Babilonia. Versión electrónica a partir de la edición de Valentina Nider. Autos completos de Calderón 61. Pamplona/Kassel: Universidad de Navarra/ Reichenberger. <http://dspace. unav.es/dspace/bitstream/10171/18216/1/61_Torre_Babilonia.pdf>. (Acceso 15 diciembre 2011).

CALDERÓN DE LA BARCA, P. (1999). El divino Orfeo (versión de 1634). Versión electrónica a partir de la edición de J. Enrique Duarte. Autos completos de Calderón 24. Pamplona/Kassel: Universidad de Navarra/ Reichenberger. $<$ http://dspace.unav.es/dspace/bitstream/10171/18182/1/24_Divino_Orfeo_16 34.pdf>. (Acceso 12 diciembre 2011). 
CALDERÓN DE LA BARCA, P. (1970). La cena del rey Baltasar en Trece autos sacramentales. Ed. José Onrubia de Mendoza. Bruguera: Barcelona. 301-353. CALDERÓN DE LA BARCA, P. 1967 (1927). El pleito matrimonial del cuerpo y el alma en Autos sacramentales, II. Ed. Ángel Valbuena Prat. Clásicos Castellanos 74. Madrid: Espasa-Calpe: 1-64.

CALDERÓN DE LA BARCA, P. (1957). La hidalga del Valle en Autos sacramentales, II. (Ed. Giacomo Vaifro Sabatelli). Clásicos Ebro 98. Zaragoza: Ebro: 54-106.

FERNÁNDEZ, L. (2008a). "La silva en la tragedia del Siglo de Oro" en Hacia la tragedia áurea. Lecturas para un nuevo milenio. (Eds. F.A. de Armas, L. García Lorenzo y E. García Santo-Tomás). Biblioteca Áurea Hispánica 55. Madrid/Frankfurt: Iberoamericana/Vervuert: 417-427.

FERNÁNDEZ, L. (2008b). "La silva: forma métrica clave en la obra dramática de Calderón”. Anuario Calderoniano 1: 105-126.

FERNÁNDEZ, L. (2010). "La silva en la comedia de capa y espada de Calderón de la Barca" Cuatro triunfos áureos y otros dramaturgos del Siglo de Oro. (Eds. A. González, S. González y L. von der Walde). México: El Colegio de México/Universidad Autónoma Metropolitana/Asociación Internacional de Teatro Español y Novohispano de los Siglos de Oro: 483-494.

HOFMANN, G. (1983). "Sobre la versificación en los autos calderonianos: El veneno y la triaca" en Calderón. Actas del congreso internacional sobre Calderón y el teatro español del Siglo de Oro, II. (Ed. L. García Lorenzo). Madrid: Consejo Superior de Investigaciones Científicas: 1125-1137.

LÓPEZ BUENO, B. (1992). "La implicación género-estrofa en el sistema poético del siglo XVI". Edad de Oro 11: 99-111.

MARÍN, D. (2000). "Función dramática de la versificación en el teatro de Calderón” en Estudios sobre Calderón, I. (Ed. J. Aparicio Maydeu). Fundamentos 162. Madrid: Istmo: 351-360.

PALOMARES, C. y PALOMARES, J. (2004). "La 'Octava real' y la épica renacentista española. Notas para su estudio". Lemir 8: 1-14.

ROZAS, J. M. (2003). Doctrina y significado del arte nuevo de Lope de Vega. $<$ http://www.biblioteca.org.ar/libros/89262.pdf>. (Acceso 28 diciembre 2011).

ROMANOS, M. (2007). "Convergencias intradramáticas y extradramáticas del soneto en el teatro de Lope de Vega" en Locos, figurones y quijotes en el teatro de los Siglos de Oro. (Eds. G. Vega García Luengos y R. Cañal). Almagro: Servicio de Publicaciones de la Universidad de Castilla-La Mancha: 407-416. RUIZ PÉREZ, P. (2001). "A propósito de la polimetría: Varias rimas y Arte nuevo." Anuario Lope de Vega 7: 67-88. 
VEGA, L. de (2006). Arte nuevo de hacer comedias. (Ed. Enrique García SantoTomás). Letras hispánicas 585. Madrid: Cátedra.

VITSE, M. (2010). "Partienda est comoedia: La segmentación frente a sí misma". Teatro de palabras. Revista sobre teatro áureo $4: 19-75$. <http://www.uqtr.ca/ teatro/teapal/TeaPalNum04Rep/TeaPal04Vitse.pdf>. (Acceso 11 Julio 2011). 
